\title{
P154 Effect of Vitamin D Deficiency on Insulin Induced Vasodilatation and Receptor Expression in Rat Model of Polycystic Ovary Syndrome
}

\author{
Bálint Bányai ${ }^{1}$, Benko Rita ${ }^{2}$, Tarszabó Róbert ${ }^{2}$, Lajtai Krisztina ${ }^{2}$, Horváth Eszter Mária², Várbíró Szabolcs ${ }^{2}$ \\ ${ }^{1}$ Semmelweis University Department of Physiology, Budapest, Hungary \\ ${ }^{2}$ Semmelweis University Department of Obstetrics and Gynaecology, Budapest, Hungary
}

\begin{abstract}
In polycystic ovary syndrome (PCOS) hyperandrogenism and metabolic dysfunction increase cardiovascular risk. Vitamin D3 deficiency is a common comorbidity in PCOS. Our aim was to examine the alterations of insulin-induced vasodilation and receptor expression in rat aorta in a PCOS model.

Methods: Female Wistar rats were treated as follows: 1. vitamin D supplemented group (D+T-); 2. vitamin D deficient (D-T-), 3. vitamin $\mathrm{D}$ supplemented with transdermal testosterone application $(\mathrm{D}+\mathrm{T}+)$ and 4 . vitamin $\mathrm{D}$ deficient with transdermal testosterone $(\mathrm{D}-\mathrm{T}+)$. Wire myograph was used for testing insulin relaxation of aorta rings in physiological salt solution and under NOS inhibition. Insulin (IR) and vitamin D receptor (VDR) density was examined by immunohistochemistry.

Results: Insulin-induced vasodilatation of the aorta rings were significantly lower in both vitamin deficient compared to the vitamin supplemented groups $(p<0.05)$. NOS inhibition significantly reduce the relaxation. Aorta endothelial IR expression was significantly higher in the vitamin $\mathrm{D}$ deficient group, meanwhile in the testosterone-treated groups $(\mathrm{D}+\mathrm{T}+\mathrm{D}-\mathrm{T}+)$ the expression was significantly lower (Area\%: $\mathrm{D}+: 0.830 \pm 0.10 ; \mathrm{D}+\mathrm{T}+: 0.298 \pm 0.06 ; \mathrm{D}-: 1.364 \pm 0.12 ; \mathrm{D}-\mathrm{T}+: 0.354 \pm 0.15, p<0.05$ in $\mathrm{D}-\& \mathrm{D}+\mathrm{T}+\& \mathrm{D}-\mathrm{T}+$ vs $\mathrm{D}+. p<0.01 \mathrm{D}+\mathrm{T}+\& \mathrm{D}-\mathrm{T}+$ vs $\mathrm{D}-)$. VDR density was significantly higher in the vitamin $\mathrm{D}$ deficient groups in comparison to the supplemented groups (Area\% VDR: D+: $41.56 \pm 5.58$ vs D-: $60.63 \pm 5.23$ ) Testosterone treatment have not any effect on VDR expression.
\end{abstract}

Conclusion: Vitamin-D deficiency causes impaired insulin induced vasodilation. Increased IR density could not compensate altered insulin-induced relaxation.

(c) 2019 Association for Research into Arterial Structure and Physiology. Publishing services by Atlantis Press International B.V. This is an open access article distributed under the CC BY-NC 4.0 license (http://creativecommons.org/licenses/by-nc/4.0/). 